\title{
Treatment of Mixed Wastes Via Fixed Bed Gasification
}

\author{
Final Report \\ September 30, 1996 - July 30, 1998
}

Work Performed Under Contract No.: DE-FC21-96MC33258

For

U.S. Department of Energy

Office of Fossil Energy

Federal Energy Technology Center

P.O. Box 880

Morgantown, West Virginia 26507-0880

By

ChemChar Research Inc. 2005 Woodlea Drive

Columbia, Missouri 65201 


\section{Disclaimer}

This report was prepared as an account of work sponsored by an agency of the United States Government. Neither the United States Government nor any agency thereof, nor any of their employees, makes any warranty, express or implied, or assumes any legal liability or responsibility for the accuracy, completeness, or usefulness of any information, apparatus, product, or process disclosed, or represents that its use would not infringe privately owed rights. Reference herein to any specific commercial product, process, or service by trade name, trademark, manufacturer, or otherwise does not necessarily constitute or imply its endorsement, recommendation, or favoring by the United States Government or any agency thereof. The views and opinions of authors expressed herein do not necessarily state or reflect those of the United States Government or any agency thereof. 


\section{DISCLAIMER}

Portions of this document may be illegible in electronic image products. Images are produced from the best available original document. 


\begin{abstract}
This report outlines the details of research performed under USDOE Cooperative Agreement DE-FC21-96MC33258 to evaluate the ChemChar hazardous waste system for the destruction of mixed wastes, defined as those that contain both RCRA-regulated hazardous constituents and radionuclides. The ChemChar gasification system uses a granular carbonaceous char matrix to immobilize wastes and feed them into the gasifier. In the gasifier wastes are subjected to high temperature reducing conditions, which destroy the organic constituents and immobilize radionuclides on the regenerated char. Only about 10 percent of the char is consumed on each pass through the gasifier, and the regenerated char can be used to treat additional wastes. When tested on a 4-inch diameter scale with a continuous feed unit as part of this research, the ChemChar gasification system was found to be effective in destroying RCRA surrogate organic wastes (chlorobenzene, dichlorobenzene, and naphthalene) while retaining on the char RCRA heavy metals (chromium, nickel, lead, and cadmium) as well as a fission product surrogate (cesium) and a plutonium surrogate (cerium). No generation of harmful byproducts was observed. This report describes the design and testing of the ChemChar gasification system and gives the operating procedures to be followed in using the system safely and effectively for mixed waste treatment.
\end{abstract}




\section{Executive Summary}

\section{Introduction}

Mixed wastes, defined as wastes that contain both RCRA-regulated hazardous constituents and radionuclides, present particular problems in the waste treatment area. Gasification has not been used much for waste treatment, but presents numerous advantages over relatively mild, but ineffective, treatment technologies and effective, but polluting high temperature oxidative incineration processes. As applied to waste treatment, gasification can be defined as the high-temperature conversion of solid and liquid organic materials to a combustible gas in an atmosphere deficient in oxygen. This report deals with the application of the ChemChar hazardous waste gasification system to the treatment of surrogate mixed wastes.

\section{Purpose}

The purpose of the research described in this report is to evaluate a 4-inch diameter continuous-feed ChemChar gasification unit for the treatment of surrogate mixed wastes. The tasks outlined in the statement of cooperative agreement objectives are (1) modification and shakedown of a laboratory-scale gasifier, (2) a test program for the treatment of surrogate wastes by the ChemChar process, (3) characterization of the solid product from the ChemChar process, (4) analysis of the process, and (5) a final report (this document). .

\section{Background}

When carbonaceous materials react at high temperatures under oxygen-deficient reactions in the presence of some water, the major products are carbon dioxide and combustible carbon monoxide and elemental hydrogen. Nascent atomic hydrogen is an intermediate in the production of elemental molecular hydrogen and is a particularly effective species in the dehalogenation of organohalide compounds. The gasification of wastes on a granular char matrix during ChemChar thermal treatment generates a combustible gas, which may be burned to destroy any unreacted wastes, if necessary, and leaves inorganic products on the regenerated char in a form in which they can be readily handled and disposed.

\section{Methodology}

Most of the efforts in the earliest stages of this research involved modification of a sub pilot scale gasifier that had been constructed by a preceding contractor. The modifications performed were necessary to enable the gasification system to operate and to do so 
safely and effectively. Cocurrently with the modifications, various shakedown runs were performed, first on a batch basis, to determine additional modifications required to make the system workable.

The char material used in the gasifier was prepared and characterized. This material is prepared by the repeated ( 3 times) gasification of subbituminous coal.

Surrogate mixed wastes were prepared in two forms. The first of these, a high organic sludge, had a high content of organic matter in the form of ethylene glycol and mineral oil. The second, neutral aqueous waste, had a relatively high water content with only very low levels of RCRA organic compounds (naphthalene, 1,2-dichlorobenzene, and chlorobenzene).

Methods were developed for the analysis of the RCRA organics, RCRA metals, and radionuclide surrogates used in the surrogate mixed wastes. The RCRA organics were determined by gas chromatography/mass spectrometry. The RCRA metals and radionuclide surrogates were determined by two methods-atomic spectroscopy (atomic absorption and atomic emission) and neutron activation analysis. Gas products were determined by column gas chromatography.

\section{Results, Conclusions, and Discussion}

The percentage destruction removal efficiencies (DRE) of the organics were based upon the fraction of organics getting as far as the activated carbon filter in the gas train of the system. For neutral aqueous waste the DREs were chlorobenzene $99.9967 \%$, dichlorobenzene $99.9982 \%$, and naphthalene $99.9976 \%$. For high organic sludge the DREs were chlorobenzene $99.9995 \%$, dichlorobenzene $99.9997 \%$, and naphthalene $99.9997 \%$.

The DREs of the RCRA metals and radionuclide surrogates were based upon the percentage of the metals exiting the gasifier. These percentages for the neutral aqueous wastes were cesium $0.002 \pm 0.0002 \%$, cerium $0.003 \pm 0.0004 \%$, chromium $0.088 \pm$ $0.047 \%$, cadmium $0.244 \pm 0.033 \%$, nickel $<0.086 \%$. and lead $<0.09 \%$. For high organic wastes the percentages were cesium $0.002 \pm 0.003 \%$, cerium $0.0056 \pm 0.003 \%$, chromium $0.052 \pm 0.026 \%$, cadmium $0.174 \pm 0.048 \%$, nickel $<0.006 \%$. and lead $<0.05 \%$.

Typical product gas compositions in mole fractions were hydrogen 0.306 , nitrogen 0.043 , carbon monoxide 0.347 , methane 0.010 , and carbon dioxide 0.307 .

This investigation has shown the feasibility of operating the ChemChar hazardous waste gasification system on surrogate mixed wastes on a continuous basis for significant lengths of time. The system is now ready to be scaled up to the minimum viable commercial size, probably a 1-foot diameter gasifier unit. 


\section{Introduction}

Mixed wastes are defined as wastes that contain both RCRA-regulated hazardous constituents and radionuclides. Because of the wide variety of both hazardous chemical (RCRA) wastes and possible radioactive materials there are many significant kinds of mixed wastes. It is estimated that the U.S. Department of Energy has responsibility for about $500,000 \mathrm{~m}^{3}$ of mixed wastes. ${ }^{1}$ The occurrence together of both hazardous chemical and radioactive wastes increases both the technical and regulatory complexities of dealing with mixed wastes. U. S. Environmental Protection Agency regulations prohibit land disposal of untreated mixed wastes. Radionuclides cannot be destroyed in any practical manner, so it is necessary to treat mixed wastes to deal with the RCRA chemical wastes. Such treatment should accomplish the following:

1. Destroy hazardous organic constituents by converting them to simple inorganic forms-carbon to carbon dioxide, hydrogen to water, oxygen to water, halogens to halide salts, and organically bound nitrogen, phosphorus and sulfur to simple inorganic compounds.

2. Remove or immobilize heavy.metals.

3. Immobilize the radionuclide constituents in a reduced volume of material suitable for ultimate disposal.

Given the refractory nature of most kinds of hazardous wastes, treatment procedures involving mild chemical processing are usually not effective. Furthermore, the toxicities of many organic constituents, heavy metals, and radionuclides, themselves, generally preclude any consideration of biological treatment. This leaves some sort of thermal process as about the only viable option for dealing with mixed wastes. Unfortunately, incineration presents some formidable problems, both real and in perception. Such problems include potential emission of toxic dioxin, acid gas production $\left(\mathrm{NO}_{\mathrm{X}}, \mathrm{SO}_{\mathrm{X}}\right)$, emission of fly ash, emission of mercury, and production of reactive, leachable bottom ash.

Some of the problems inherent to incineration and related processes, such as plasma treatment, can be overcome by using gasification treatment. As applied to waste treatment, gasification can be defined as the high-temperature conversion of solid and liquid organic materials to a combustible gas in an atmosphere deficient in oxygen. Typically, the gas product of gasification contains noncombustible carbon dioxide, along with combustible carbon monoxide, elemental hydrogen, and, with some processes, significant quantities of hydrocarbon gases, particularly methane. 


\section{Purpose}

The purpose of the research described in this report is to evaluate a 4-inch diameter continuous-feed ChemChar gasification unit for the treatment of surrogate mixed wastes as outlined in the following excerpted from the written Cooperative Agreement under which the research was performed:

\section{STATEMENT OF COOPERATIVE AGREEMENT OBJECTIVES}

The objective of the work under this cooperative agreement was to conduct research in five tasks. The overall objective of the cooperative agreement was to construct a gasifier for evaluating the effectiveness of the Chemchar process to reduce the volume and potential hazards of a low level mixed waste.

Task 1: Modification and Shakedown of a LaboratoryScale Gasifier

The Participant will develop or modify a laboratoryscale gasifier. The effect of this effort will be to produce a laboratory-scale gasifier (approximately 4 inches in inside diameter) which can be used to evaluate the Chemchar gasification process. The resulting gasifier will be evaluated through shakedown testing prior to the formal test program. The resulting gasifier shall include, but not be limited to, the following features: ability to measure the product gas flow, gas sampling ports, feed hopper, char filter, gas line filter, ignition system, and a process temperature measurement system.

Hardware shakedown shall include but not be limited to the following: calibration of monitors and controllers, assessment for gas leaks, development of ignition procedures, and operation in a continuous mode. During shakedown the Participants will measure the salient parameters to assess and establish steady state operation. 
Task 2: Test Program for the Treatment of Surrogate Wastes by the Chemchar Process

The Participants will prepare and characterize the char used in the Chemchar process. This characterization/analysis shall include, but not be limited to, measurement of moisture, volatiles, porosity, density, surface area, reactivity, and proximate and ultimate analysis.

The Participants will choose surrogate wastes. The wastes will be approved by the COR prior to testing. The surrogate wastes will be prepared in accordance with DOE guidelines (DOE Publication, "Surrogate Formulation for Thermal Treatment of Low-Level Mixed Wastes-Part II: : Selected Mixed Waste Treatment Project Waste Streams").

The Participant will determine for the Chemchar process, through repeated testing, the optimum operating parameters for the destruction and volume reduction of low level mixed wastes.

Task 3: Characterization of the Solid Product from the Chemchar Process

The Participant will characterize the final solid product from the above test program. This characterization shall include, but not be limited to, leachability assessment, and an assessment of the physical and chemical form of the solid product.

\section{Task 4: Analysis of the Process}

The Participant will evaluate the process from a cost assessment perspective. The evaluation/assessment will include, but not be limited to, the use of consumables, the ability to recycle char, product gas yield, yield of all condensates, and etc. The Participant shall also assess the reactor temperature profiles and heat transfer in order to perform a thermodynamic analysis. 
Task 5: Final Report

A final report will be produced and delivered to the DOE within 60 days after completion of Task 4 .

\section{Background}

\section{Advantages of Gasification for Hazardous Waste Treatment:}

Gasification, as a thermal waste treatment method, possesses several distinct advantages over incineration. First, the volume of gas produced by gasification is only about one third the gas volume produced by incineration, so that a much lower volume of gas requires treatment. Even after the gases produced by incineration have been properly treated there is essentially no use for them, whereas the gas products of gasification can be burned to generate power or even used as raw materials in chemical synthesis.

A major environmental advantage of gasification is that the oxides of nitrogen and sulfur are not produced. During gasification nitrogen in wastes goes to elemental $\mathrm{N}_{2}$; the small volume of nitrogen gas produced acts only as a minor diluent of the product gas. A small amount of ammonia can be produced during gasification; however, the ammonia gas is readily condensed out of the gas phase and collected. Rather than producing $\mathrm{SO}_{2}$ and $\mathrm{SO}_{3}$, gasification produces $\mathrm{H}_{2} \mathrm{~S}$. Although hydrogen sulfide is quite toxic it can be readily removed from the product gas by standard purification methods.

Some of the greatest advantages of gasification result from the high temperatures and the reducing environment under which gasification is carried out. The high temperatures increase the destruction efficiency of thermally stable compounds. The reducing environment decreases the probability for the formation of PCDFs and PCDDs (so-called de novo synthesis of dioxins and dibenzofurans). Virtually all organically bound chlorine is converted to inorganic chloride, which is retained by solids inside the gasifier or scrubbed as $\mathrm{HCl}$ from the gas produc. In contrast, simple pyrolysis of wastes containing halogenated organics by heating in an inert atmosphere yields liquids and chars that are too contaminated with chlorine derivatives to be utilized as fuel substitutes.

Whereas incineration produces an ash, gasification, which operates under oxygendeficient conditions, can be operated to produce a solid char residue, which can be used to advantage to sequester byproducts of waste destruction. Gasification is especially advantageous for the treatment of mixed wastes containing both hazardous organic and radioactive waste, for which incineration cannot generally be used. It is possible to sequester metals on the char solid product of gasification to minimize the potential for leaching. Since gasification subjects metals to a reducing environment, there is less of a tendency for the production of metal oxides which can pose problems during incineration. 


\section{Principles of Gasification:}

Gasification can be defined as a process by which carbonaceous solids are reacted with one or more other reagents to produce combustible gases and vapors. Substances with which carbonaceous solids may be reacted to cause gasification to occur include oxygen, water, carbon dioxide, and hydrogen. As distinguished from combustion however, gasification always uses a substoichiometric amount of oxidizer relative to combustible material present so that a reduced gas product is evolved. Therefore, gasification can be considered to be combustion under oxygen starved conditions.

The two major products from the gasification process are synthesis gases and fuel gases. Fuel gases consist of combustible $\mathrm{CO}, \mathrm{H}_{2}$ and small amounts of $\mathrm{CH}_{4}$. The synthesis gas has a higher $\mathrm{H}_{2}$ content and is used in a second step to produce organic chemicals. The success of gasification in destroying hazardous wastes lies in its chemistry. Therefore, it is important to consider the major reactions involved in the gasification process. The primary heat yielding reaction in the gasification process is the reaction of oxygen with carbon to produce carbon dioxide:

$$
\mathrm{C}+\mathrm{O}_{2} \rightarrow \mathrm{CO}_{2}+\text { heat } \quad \mathrm{H}=-94.05 \mathrm{kcal} / \mathrm{mol}
$$

The partial oxidation of carbon is one of the two primary overall reactions that yields combustible gas during the gasification of carbonaceous solids:

$$
\mathrm{C}+1 / 2 \mathrm{O}_{2} \rightarrow \mathrm{CO}+\text { heat } \quad \mathrm{H}=-26.42 \mathrm{kcal} / \mathrm{mol}
$$

This reaction is exothermic; however, the reaction does not stop at CO. Any free oxygen present will react with $\mathrm{CO}$ to produce $\mathrm{CO}_{2}$. Therefore, for a fuel rich system in which excess hot carbon is present the slower endothermic reaction

$$
\mathrm{C}(\mathrm{s})+\mathrm{CO}_{2}+\text { heat } \rightarrow 2 \mathrm{CO} \quad \mathrm{H}=41.2 \mathrm{kcal} / \mathrm{mol}
$$

also occurs. The carbon monoxide produced in the above reactions is one of the two major reducing gases produced by gasification; the other is hydrogen, which is produced by the oxidation of carbon by steam.

$$
\mathrm{H}_{2} \mathrm{O}+\mathrm{C}+\text { heat } \rightarrow \mathrm{H}_{2}+\mathrm{CO} \quad \mathrm{H}=31.4 \mathrm{kcal} / \mathrm{mol}
$$

An intermediate step in this reaction is the production of nascent hydrogen (atomic hydrogen) which then combines to produce hydrogen gas:

$$
\begin{aligned}
& \mathrm{H}_{2} \mathrm{O}+\mathrm{C}+\text { heat } \rightarrow 2\{\mathrm{H} \cdot\}(\text { nascent hydrogen })+\mathrm{CO} \\
& 2\{\mathrm{H} \cdot\} \rightarrow \mathrm{H}_{2}
\end{aligned}
$$


The production of nascent hydrogen is extremely important in gasification of hazardous waste because the highly reactive $\{\mathrm{H} \cdot\}$ is extremely effective in destroying refractory organic compounds while preventing the production of undesirable byproducts such as dioxins.

Methane is also a gasification product gas and is produced in the gasifier reactor by the reaction of carbon with hydrogen:

$$
\mathrm{C}+2 \mathrm{H}_{2} \rightarrow \mathrm{CH}_{4}
$$

\section{ChemChar Gasification:}

The ChemChar process ${ }^{2}$ has been studied extensively for the destruction of a variety of wastes. Among the wastes that have been studied are refractory organic waste sludges including those containing both PCBs and heavy metals, mixed wastes containing organic substances and radioactive materials, sewage sludge, spent activated carbon, and contaminated soils. The ChemChar gasifier is a cocurrent flow gasification system, which is the best configuration for gasification waste treatment. Cocurrent flow means that the wastes, oxidant gas, regenerated solids, and gaseous products all flow the same way through the gasifier as shown in Figure 1. With the ChemChar gasifier system, a narrow incandescent thermal zone (ITZ) is maintained in the mid-portion of the gasifier. It is in this zone that the gasification reactions outlined above occur, and any waste entering the gasifier has to pass through the ITZ and thus be subjected to treatment before exiting the unit.

For most ChemChar applications gasification is carried out on a matrix of macroporous char. Figure 2, is an electron micrograph of triple-reverse-burn char (TRB char) typically used in the ChemChar process. The char is produced from subbituminous coal from Hanna, Wyoming, in a cocurrent flow gasifier reactor similar to the reactor outlined in Figure 1. In the gasifier reactor a high-temperature $\left(>1500^{\circ} \mathrm{C}\right)$ thermochemical gasification zone moves through the column of coal toward the incoming oxidant. This "reverse-burn" process is repeated three times to produce TRB char which has many beneficial properties:

- Highly macroporous with a surface area of around $200 \mathrm{~m}^{2} / \mathrm{g}$

- Inexpensive to produce

- Sorbs a wide variety of wastes, both organic and inorganic

- Ideal matrix for mixing, drying and retention of sludges

- The carbonaceous surface provides a matrix on which thermochemical reactions can occur under controlled conditions. 


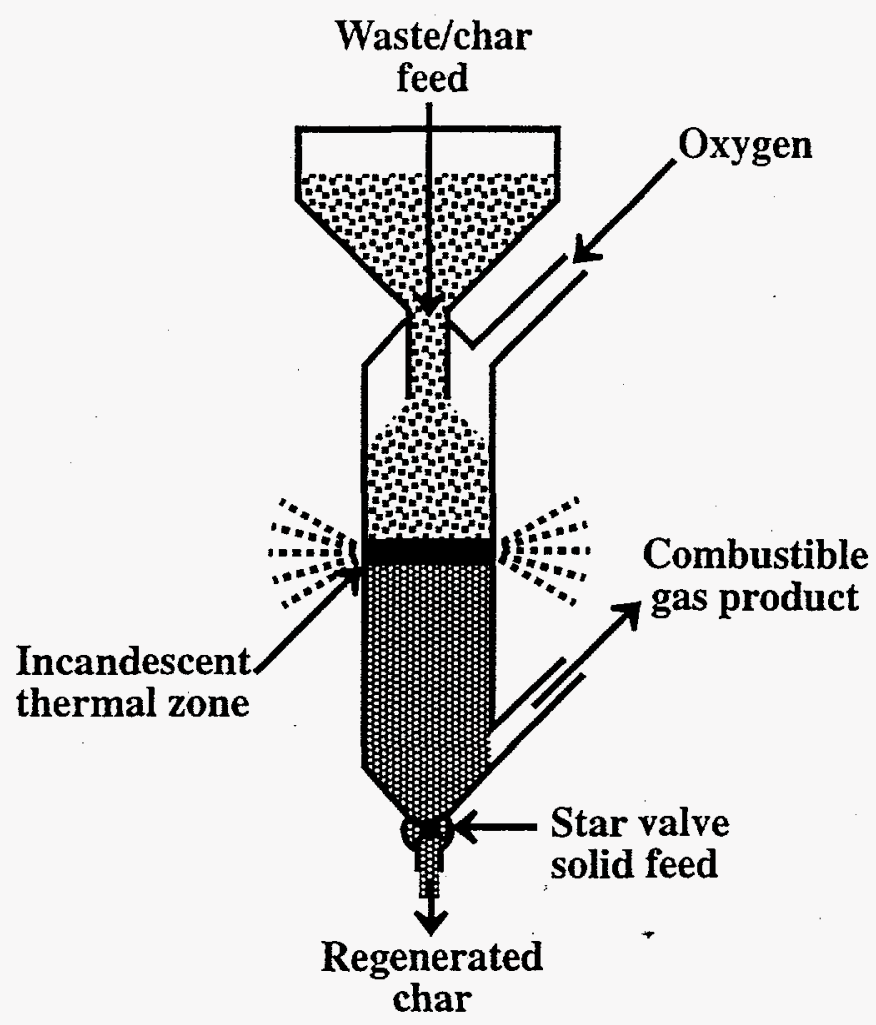

Figure 1. A continuous-feed cocurrent flow ChemChar gasifier. Because of a large excess of carbon, the overall process is reducing and a combustible gas is formed. The gás product is commonly run through a condenser and char filter, then flared or oxidized in a packed bed flameless oxidizer.

Due to the properties of TRB char, liquid, solid, gaseous and sludge wastes can be treated by the ChemChar process. Liquid wastes can be sorbed directly onto the char surface. Aqueous wastes can be filtered through a bed of char to remove hazardous materials, the water discharged, and the char dried and gasified. Waste sludges can be mixed directly with char; solvents may be added to prevent agglomeration. The char particles act to dry these types of wastes through capillary action of the micropores of the char. Solid waste can be macerated and mixed directly with char before being fed into the reactor.

Once char/waste mixing is complete, the mixture is gasified in a reactor as shown in Figure 1. Energy for the process is generated by exothermic reaction of oxygen with the reactor charge consisting of coal, char, or waste materials sorbed on the char. Heat generated by these reactions pyrolyzes wastes sorbed to or mixed with the carbon and provides energy for endothermic reactions (see Reactions 1 and 2) to occur in the downstream end of the gasification zone. The products of these reactions are reducing gases which create a strongly reducing atmosphere behind the flame front. This reducing characteristic of the 


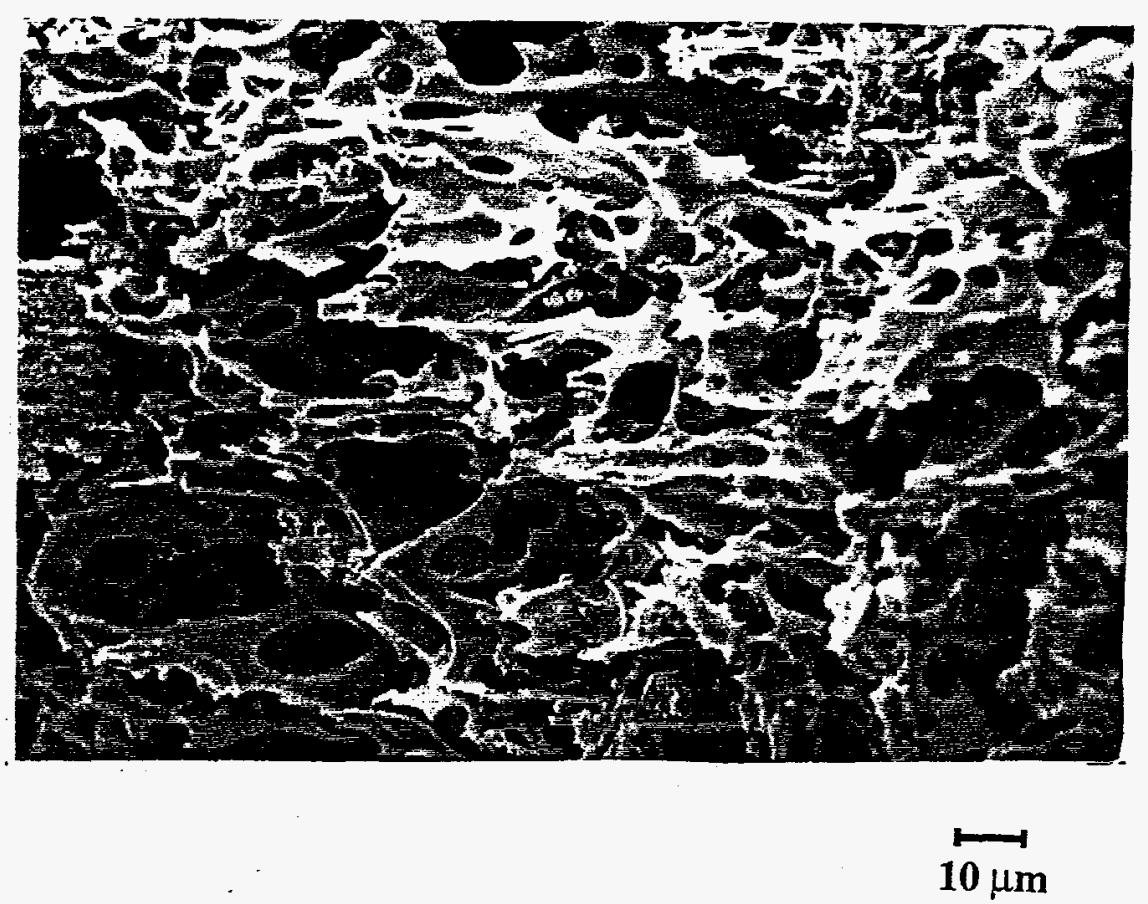

Figure 2. Electron micrograph of macroporous char used as a waste carrier, fuel, and byproduct retention medium in ChemChar waste gasification.

gasification process effectively destroys refractory organic compounds without producing undesirable by products.

The ChemChar gasification process is applicable to the treatment of several kinds of wastes that are difficult to handle with conventional technologies. One of the best types of wastes to treat by the ChemChar gasification process are refractory organic sludges, which may contain heavy metals. An example of this type of waste would be a sludge containing PCBs mixed with lead, cadmium, mercury, and other heavy metals. Gasification of such a waste destroys the organic constituents while retaining the hydrogen chloride byproduct and heavy metals on the char matrix. Although mercury is evolved, it is collected from the gas by a cold char filter downstream.

Another type of waste that is quite troublesome to treat by conventional means, but is easily handled by cocurrent flow gasification is mixed wastes containing hazardous organic materials and radionuclides. Gasification destroys the organic constituents while leaving the radioactive materials on the char matrix. With the radionuclides firmly sequestered to the char, the char residue can be subjected to countercurrent flow gasification or to incineration to reduce the mass of the residue to a minimum quantity in a form that is resistant to leaching. 
The treatment of mixed wastes containing radioactive technetium- $99 \mathrm{~m}$ and surrogate mixed wastes containing nonradioactive strontium and cesium have been studied. ${ }^{3}$ For this study, technetium-99m was bound as the oxyanion to an anion exchange resin and nonradioactive $\mathrm{Cs}^{+}$and $\mathrm{Sr}^{+}$were bound to a cation exchange resin. These materials were mixed with char and gasified, and the potential release of the metals from the gasifier was determined.

In the case of cesium- and strontium-spiked surrogate wastes, no metal was found in the trapping solutions used to trap metals from the gas product. The metals were completely retained on the solid product. In the case of technetium- $99 \mathrm{~m}, 99.9 \%$ of the technetium was retained by the char in the gasifier. The remaining $0.1 \%$ of the activity was recovered as condensate and sorbate downstream. The process reduced the waste to only $2 \%$ of its original volume.

Contaminated soils, another form of waste difficult to treat by traditional means, can be gasified after mixing with with char that acts as a fuel for the gasification process. Or the soil may be converted to a granular form and soaked in asphalt or oil and gasified directly in the absence of char. Gasification conditions can be adjusted such that the soil is slagged to a poorly leachable fused material.

The gasification of soil contaminated with hydrocarbons, PCBs, and thorium and spiked with zinc, lead, and copper was studied. ${ }^{4}$ A soil/char mixture of $35 \%$ soil, $65 \%$ char was subjected to ChemChar gasification followed by counter current flow gasification to convert the soil mineral matter to a slaggy ash. Analysis of the combustion gas demonstrated greater than $99.9999 \%$ DRE of PCBs; and no evidence for the presence of chlorinated dibenzofurans or chlorinated dibenzodioxins. Spiked metals from the gaseous effluent were collected in an acid oxidizing trapping solution. More than $98 \%$ of lead and greater than $99 \%$ of $\mathrm{Cu}$ and $\mathrm{Zn}$ were retained by the solid in the gasifier. Leaching tests, using $0.5 \mathrm{M}$ acetic acid, indicated that only $2.2 \%$ of the spiked zinc, $5.7 \%$ of the spiked $\mathrm{Pb}$ and $2.3 \%$ of the spiked $\mathrm{Cu}$ were leached from the gasification residue.

The chlorine in the chlorinated PCB compounds in the waste soil was collected from the gas stream in base traps and leached from the solid residues. A total of $93 \%$ of the chlorine originally in the waste was recovered from the solid waste residues supporting the low production of chlorine emissions from the organochlorine compounds during gasification.

Hexachlorobenzene, $\mathrm{HCB}$, a completely chlorinated aryl hydrocarbon, is a nonvolatile, thermally and chemically stable compound that has been used as a surrogate compound for other refractory organic wastes such as PCBs. Experiments with HCB gasification have shown that only $0.01 \%$ of the HCB was carried with the product gas out of the gasifier corresponding to a DRE of $99.99 \%$. A particularly significant finding was the total absence of any detectable chlorinated dibenzofurans and dibenzodioxins. ${ }^{5}$ 


\section{Methodology}

\section{Modification and Shakedown of a Sub Pilot Scale Gasifier:}

The ChemChar gasifier system discussed in this report is shown schematically in Figure 3. It is a cocurrent gasifier designed to operate in a continuous feed mode and was modified from an earlier reactor design used in the ChemChar laboratory. The gasifier feeds wastes sorbed to a granular macroporous char matrix from an upper feed hopper, through a 4-inch diameter, 4-foot long stainless steel gasifier reactor tube in which gasifiable organic constituents of the wastes are subjected to high-temperature reducing conditions that convert the wastes to simple inorganic materials. The spent char from gasification is metered through a star valve, which regulates material flow through the system, and into a cylindrical collection hopper. Gas products of the gasification reaction are allowed to flow from the bottom of the gasifier through a gas handling system. The major components of the gas processing system consist of (1) a water-cooled condenser, (2) a filter packed with untreated TRB char, and (3) a flare in which the gas products are burned prior to discharge through a fume hood.

The continuous feed ChemChar gasifier system usëd in this research was originally constructed under an earlier DOE contract with another concern other than ChemChar. However, the original design and construction were seriously flawed. Therefore, much of the material in this report deals with modifications of the earlier gasifier and its associated gas train and other features.

The shakedown of the gasifier was divided into two major phases. The first of these was a preliminary shakedown in which gasification was not carried out on a prolonged basis. The main aspects of preliminary shakedown were calibration of monitors and controllers, evaluation of safety blowouts, elimination of gas leaks, and the development of an ignition procedure. The actual shakedown phase consisted of development of a standard operating procedure including establishment of initial operating parameters, standardization of a systematic startup procedure, development of methods and procedures to monitor and control the system during continuous mode operation, and measurement of a thermal profile for the reactor during operation.

\section{Modification of Gasifier:}

The slide valve originally provided with the feed hopper was removed. This valve was initially put in place to minimize the flow of product gases back into the feed hopper and to minimize accumulation of oxygen in the hopper. Presently this objective is accomplished using nitrogen flow to slightly pressurize the hopper. This use of nitrogen purges startup air from the hopper with inert nitrogen gas, minimizes oxygen levels in the hopper, and keeps flammable gases pushed out of the hopper. An additional modification 


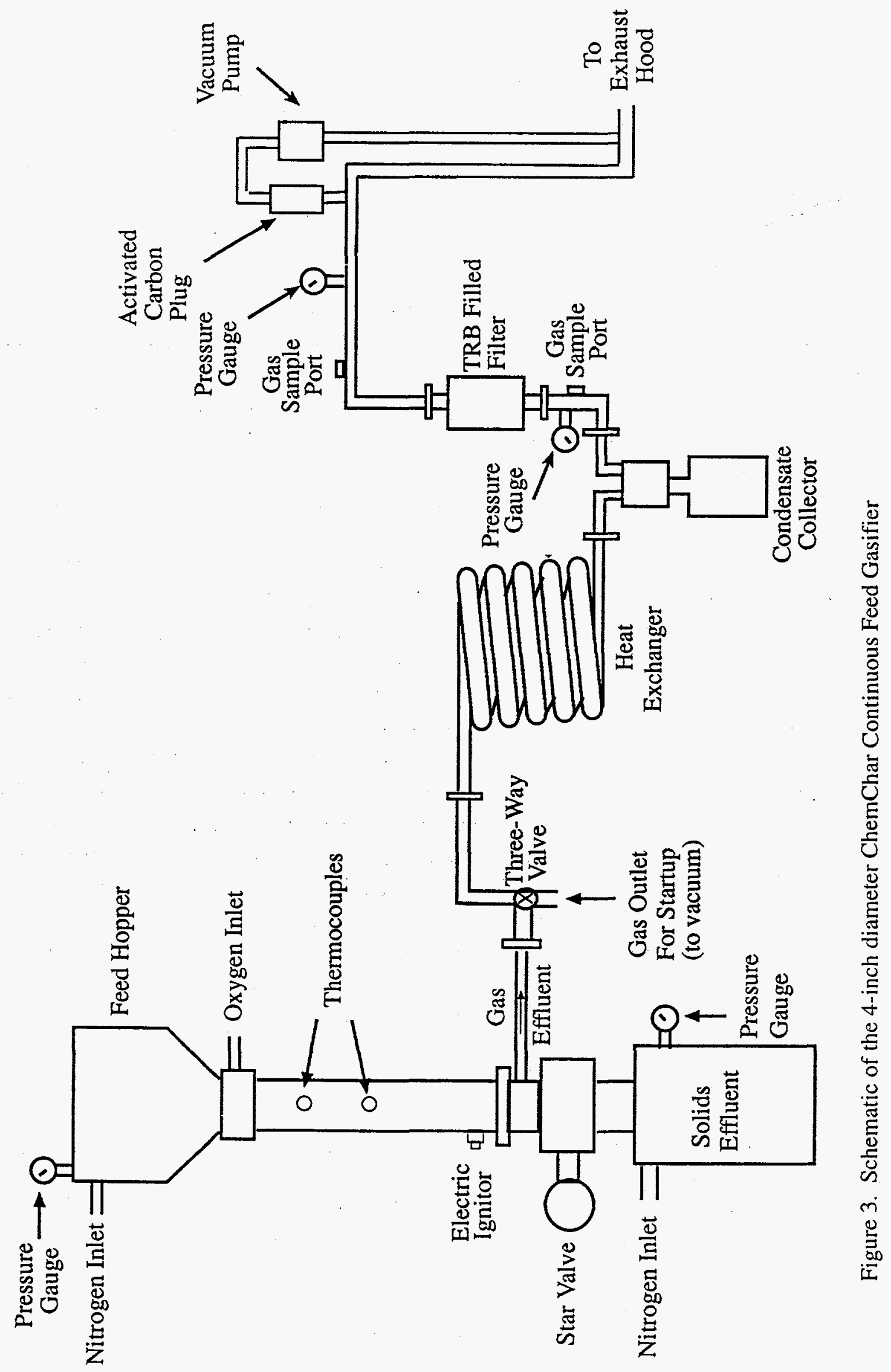


to the hopper was the installation of a quartz window at the base of the hopper that facilitates in the observation of char levels in the hopper.

The lid of the feed hopper, initially a single piece of spun stainless steel, was modified to enable pressure relief in the event of a buildup of excess pressure or an explosion in the hopper. A 12" diameter piece was sawn from the center of the lid and subsequently epoxied back place. This functions to weaken the structure, which in case of explosion would direct the explosion upward away from workers at the floor and platform levels. This modification functions only to back up the $2^{\prime \prime}, 5$ psi (at $21^{\circ} \mathrm{C}$ ) rupture disk mounted on the side of the hopper.

The lower hopper was also modified for explosion management. A 12 " by 12 " square was cut from the side of the hopper. This piece was secured back into place with epoxy and fiberglass. The weakened area of the lower hopper is positioned toward the blast shields present in the laboratory. A slight flow of nitrogen is also used to prevent accumulation in the lower hopper of flammable gas and/or oxidants at startup and during operation.

The original char filter was much too large with a large amount of open space, which constituted a major explosion hazard, so it was redesigned to be smaller and more practical. It is now constructed from a 2 ' long section of 4 " i.d., schedule 40 , stainless steel pipe. The ends are capped with $5 "$ o.d. flanges welded in place and threaded to accomodate entry and exit pipes. A metal tank mounted suction strainer of 30 -mesh stainless steel is threaded into the inlet side of the filter. The strainer functions to contain the char in the filter and decrease back pressure. The exit hole is covered with a 30-mesh stainless steel screen to prevent large particles from exiting the filter with the product gas.

The original gasifier unit was equipped with a radiofrequency (RF) unit designed to apply power to char contained within a 4 " i.d. ceramic (alumina) tube that constituted the core of the gasifier unit. This ignition source did not work and in any case could not have been used with the stainless steel gasifier core that replaced the ceramic unit. The RF ignitor system was replaced with a 3/8" o.d., 3" long, 375 watt, cartridge heater entending directly into the char flow. This unit was mounted in the product gas outlet fitting directly below the gasifier core. A variable voltage autotransformer is used to apply 80 volts $(\sim 170$ watts) to the igniter for 5 minutes to heat the char to ignition. The heater is easily removed and replaced when failure occurs.

The cyclone originally supplied with the system was removed and replaced with 1" pipe. Initial operation of the unit showed that the levels of particulate matter emitted were very low, and the gas flow rate was too low to enable a cyclone to operate. Its removal eliminated a significant product gas dead volume in the system that posed an explosion hazard.

The thermocouple system installed in the original ceramic core to measure temperature did not work to measure temperatures accurately in real time because of the insulating qualities of the alumina ceramic material. The replacement of the original ceramic core with 
a 4" schedule 40 , stainless-steel core necessitated installation of a new system to monitor temperatures and hence the location of the incandescent thermal zone (ITZ) in which gasification reactions occur. This was done by mounting two shielded $\mathrm{K}$-type thermocouples through the side of the core at strategic locations and a third thermocouple extending from the center of the feed hopper down into the center of the gasifier core with the leads exiting out the side of the feed hopper near the top of the gasifier unit. A simplistic, but surprisingly effective means of determining the location of the ITZ was to simply squirt water on the outside of the core and observe its evaporation.

A key mechanical aspect of the gasifier is the separation of product gas from char that has passed through the ITZ. This is done in a separate unit mounted immediately below the gasifier core. The original piece designed for that purpose exhibited a strong tendency to clog the gas exit port with finely divided particulate matter, which resulted in increased core and hopper pressures, so it was replaced by a unit of improved design. The new design decreases gas velocity by increasing the capacity, increases the separation screen area, and locates the screen in a horizontal position at a level significantly above the char outflow. It performed well in the continuous-feed mode without clogging.

The conical stainless steel condensate collector was removed and replaced with a 1 liter high density, polyethylene bottle. This bottle decreased the dead volume and provided a member that would not create a hazard during explosion. The modification was influenced by a gas explosion in the condensate collector that occurred during gasifier startup when the stainless steel collector was still installed. The replacement of the steel collector combined with changes in the startup procedure has minimized the risk of a dangerous explosion in this part of the gasifier.

A stainless steel 3-way valve was placed in line at the product gas exit from the reactor core. This valve is used to bypass the primary product gas train during ignition. During ignition the valve is used to divert the gas product to a vacuum pump (KNF model UN726FTP, 115 VAC $60 \mathrm{~Hz} 1.2 \mathrm{amp}$ ) which exhausts directly into the fume hood. This setup allows air to be drawn into the system during ignition thus decreasing the risk associated with ignition with pure oxygen.

Total product gas flow is measured with a Dwyer RMC series rotometer capable of measuring flows in the range of 0 to 10 standard cubic feet per minute (SCFM) air. This meter is of an appropriate size to measure total gas flow of the product. The gas volume produced is then estimated from the run time and the gas flow rate. The rotometer was installed in the product gas train directly following the char filter. It has a bypass valve which allows the product gases to be directed though the rotometer.

Gas samples for analysis are taken from two ports that were installed preceding and following the char filter. The ports consist of $1 / 4$ " brass ball valves with a septum placed in the outlet side of the valve. The gas samples are taken with a gas-tight syringe and analyzed by gas chromatography (GC). 
In addition to the gas sampling ports, a gas-sampling loop was installed in the primary off gas train. It is filled with activated carbon, which acts as an absorbent and functions to trap semi-volatile organic compounds (SVOC) and some volatile organic compounds (VOC) for qualitative and quantitative determination. The location of the gas sampling loop allows for the calculation of destruction removal efficiencies (DRE) by the gasification system exclusive of the gas flare.

$$
\mathrm{DRE}=\frac{\text { Mass compound treated }- \text { Mass compound recovered }}{\text { Mass of compound treated }} \times 100
$$

The loop is located in the gas stream past the condenser and char filter, but before the product gas flare It is teed off from the primary off gas train and consists of a $3 / 8$ " pipe that extends into a 5" long, 1-3/4" i.d., stainless steel cartridge filled with approximately 80 $\mathrm{g}$ of activated carbon as an adsorbent. The loop continues from the cartridge into a vacuum pump (KNF model UN035.1.2 STP, $115 \mathrm{VAC}, 60 \mathrm{~Hz} 3.75 \mathrm{amp}$ ), through an Omega D7164 glass ball rotometer, and then back into the primary product gas train immediately before the flame arrestor at the terminus of the system.

Three additional rupture disks, of in-house design, were placed in the off gas train, one 8 " from the product gas outlet piece, one directly preceding the char filter, and one following the char filter. The rupture disks are constructed of 2-1" by $41 / 4$ " 304 stainless steel mating flanges. Lightweight aluminum foil is sandwiched between the flanges. Tests showed that these disks rupture at an average of 8 psi with air at $21^{\circ} \mathrm{C}$. The foil inserts are replaced between each run.

Additional safety shielding was installed to protect the area used as a control center for the gasifier. The shield consists of a $1 / 4^{\prime \prime}$ thick, 3.5' wide, $8^{\prime}$ high steel panel. The shield was braced to existing room shielding and anchored to the floor. A polyurethane window was installed to allow operators to view the gasifier in operation. Control valves and operation monitors were mounted behind the shield to provide for operator safety. Additional pressure gauges were mounted behind the shield to monitor pressures in the feed hopper, lower hopper, and the offgas train (both before and after the char filter). The control for the igniter was also mounted on the shield.

The flow rate of the variable speed star valve was initially found to be too fast even at the lowest speed setting. This was corrected by changing the drive sprockets to slow the speed of the valve revolution.

\section{Preliminary Gasifier Shakedown}

\section{Char Preparation and Characterization:}

The granular "triple-reverse-burn" (TRB) char used in the process was prepared from Hanna Basin (Wyoming) non-swelling subbituminous coal. The coal was ground and 
sieved to 14-18 mesh size, then converted to char via three subsequent gasifications. Gasification was carried out in $21 / 2$ inch diameter steel pipes mounted vertically with oxygen flow inward through the bottom of the pipes, which were open at their tops. Granular coal in each pipe was ignited by exposing the top of the coal plug to a propane torch flame with oxygen flowing through the granular material. The "flame front" thus established advanced downward through the granular coal toward the oxygen inlet, converting volatile matter to gas and leaving a char. This char product was gasified two more times after addition of $10 \%$ water before each subsequent gasification. The TRB char is a low-grade activated carbon that has been analyzed for moisture, volatile matter, porosity, density, surface area, and reactivity. Proximate and ultimate analysis of the char are presented in Table 1.

Table 1. Proximate and Ultimate Analysis of TRB Char

Consituent As Received Moisture Free Moisture and Ash wt. \% wt. \% $\quad$ free wt. \%

Proximate Analysis

Moisture

Ash

Volatile Matter

Fixed Carbon

Total

Heating Value

(BTU/lb.)
2.29

12.28

9.71

75.72

100.00

12,143

\section{Ultimate Analysis}

Moisture

Hydrogen*

Carbon

Nitrogen

Sulfur

Oxygen*

Ash

Total
2.29

0.40

82.47

1.46

0.77

0.33

12.28

100.00
12.57

9.94

77.49

100.00

12,428
11.37

88.63

100.00

14,215

* Hydrogen and oxygen values do not include hydrogen and oxygen in the free moisture associated with the sample. 
Waste Selection and Preparation:

Two types of wastes were prepared for this study, a high organic sludge and a neutral aqueous sludge. Components of these wastes are representative of several high volume mixed wastes currently stockpiled by the DOE. The wastes were prepared according to standard laboratory procedure. The compositions of these wastes are given in Table 2.

Table 2. Composition of DOE surrogate wastes

High organic sludge

Component

Name

Bulk ingredients

Activated Carbon

Water

Perlite

$\mathrm{Fe}_{2} \mathrm{O}_{3}$

$\mathrm{CaSO}_{4} \cdot 2 \mathrm{H}_{2} \mathrm{O}$

$\mathrm{Al}_{2} \mathrm{O}_{3}$

Ethylene glycol

Mineral Oil

RCRA metals

$\mathrm{CrCl}_{3} \cdot 6 \mathrm{H}_{2} \mathrm{O}$

$\mathrm{NiCl}_{2} \cdot 6 \mathrm{H}_{2} \mathrm{O}$

$\mathrm{PbCl}_{2}$

$\mathrm{CdCl}_{2} \cdot 2.5 \mathrm{H}_{2} \mathrm{O}$

RCRA organics

Naphthalene

1,2-Dichlorobenzene

Chlorobenzene
Weight $\%$

10 Activated Carbon

20 Water

10

10

10

5

14.5

12.0

Name

Bulk ingredients

$\mathrm{CaCl}_{2}$

$\mathrm{NaHCO}_{3}$.

$\mathrm{MgSO}_{4} \cdot 7 \mathrm{H}_{2} \mathrm{O}$
Neutral aqueous waste

Component

Weight \%

10

75

3

3

3

2.5

1

Radionuclide surrogate

$\mathrm{CeCl}_{3}$

$0.25 \mathrm{Cr}\left(\mathrm{NO}_{3}\right)_{3} \cdot 9 \mathrm{H}_{2} \mathrm{O} \quad 0.25$

$0.25 \mathrm{Ni}\left(\mathrm{NO}_{3}\right)_{2} \cdot 6 \mathrm{H}_{2} \mathrm{O} \quad 0.25$

$0.25 \mathrm{~Pb}\left(\mathrm{NO}_{3}\right)_{2} \quad 0.25$

$0.25 \mathrm{Cd}\left(\mathrm{NO}_{3}\right)_{2} \cdot 4 \mathrm{H}_{2} \mathrm{O}$

0.25

$\mathrm{CsCl}$
0.25
$\mathrm{CeCl}_{3}$
0.25
$0.25 \mathrm{CsCl}$

\begin{tabular}{ccccc} 
& 0.25 & $\mathrm{CeCl}_{3}$ & & 0.25 \\
Total & 0.25 & $\mathrm{CsCl}$ & & 0.25 \\
\cline { 2 - 4 } & 100.0 & & Total & 100.0
\end{tabular}

0.4

2 1,2-Dichlorobenzene

0.3

Chlorobenzene

0.3 


\section{Calibration of Monitors and Controllers:}

The gas flow meters were calibrated using a liquid displacement method. The flow meters calibrated by this method included the Dwyer RMC series used for total flow, the Omega D7164 glass ball flow meter used for measuring the sample loop, and the Omega N015 glass ball flow meter used to deliver oxygen during gasification. Typical flows of total product gas flow range from 45 to $55 \mathrm{~L} / \mathrm{min}$. The sampling rates for the carbon filter range from 18 to $22 \mathrm{~L} / \mathrm{min}$. The oxygen delivery rates to gasifier range from 10 to 30 $\mathrm{L} / \mathrm{min}$.

\section{Ignition Preparation and Procedure:}

Preparation for operation of the gasifier plays a large role in operation safety, efficiency, and evaluation. Between each run there is complete maintenance of the system that includes disassembly and cleaning, Normal cleaning consists of brushing with soap and water, a water rinse, and an acetone rinse. The maintenance allows for the replacement of gaskets and seals to maintain the integrity of the system. All parts are visually inspected to determine if wear or corrosion damage has occurred; if deemed necessary, these parts are replaced.

Once the system is cleaned and reassembled the system is sealed and pressurized to 3 psi with nitrogen. Joints and seals are then checked for leaks using soapy water. Leaks are repaired wherever encountered.

\section{Run Checklist:}

Safety is the number one concern during operation of the gasifier, which led to the development of a standardized startup procedure. A checklist is used for each run to confirm that steps are followed. The startup checklist is given in Figure 4.

\section{Typical Run:}

This section outlines a typical gasifier run. Details vary with the type of waste treated.

The gasifier is first charged with a char-waste mixture. A blank plug of $2 \mathrm{~kg}$ wastefree TRB char premixed with $5 \%$ water is placed in the bottom of the gasifier in contact with the cartridge heater. The plug allows for the initiation of a uniform ITZ before it reaches the char/waste mixture, which is loaded on top of the blank plug. A 15-kg charge of the char/waste mixture is placed in the feed hopper and allowed to flow downward to contact the blank plug of TRB char. During a normal run $12 \mathrm{~kg}$ of the char/waste mixture is gasified. 
Figure 4. The ChemChar 4" Gasifier Operation Checklist.

ChemChar 4" Continuous Feed Gasifier Startup Checklist

Turn on nitrogen and saturate system.

Decrease nitrogen flow to a minimum.

Turn on condenser water valve.

Open vacuum/condenser valve to vacuum side.

Open the air inlet valve.

Turn on igniter at $70 \%$ voltage setting, wait 5 minutes.

Shut air inlet valve.

Turn off igniter.

Start the oxygen flow of $10 \mathrm{~L} / \mathrm{min}$, after 2 minutes increase flow to $20 \mathrm{~L} / \mathrm{min}$. Amount of time to confirm ITZ formation by water evaporation method.

Record the amount of time to confirm thermal zone 4" into gasifier cylinder. Open the vacuum-condenser valve to the condenser position. Turn off vacuum pump.

Ignite off gases with Bunsen burner.

Start star valve to feed char/waste mixture.

ChemChar 4" Continuous Feed Gasifier Shut Down Checklist

Shut oxygen valve.

Stop star valve.

Increase nitrogen flow to $15 \mathrm{~L} / \mathrm{min}$ into top hopper until off gases no longer ignite.

Decrease nitrogen flow to a minimum for an hour before shutting it off.

Run Notes: 
The hopper lid is sealed into place with silicone caulk and allowed to cure for 30minutes before initiation of the ITZ. While the silicone caulk is curing, the portion of the gasifier through which the product gas exits is heated with heating tape to above $100^{\circ} \mathrm{C}$ to prevent condensation of water that may plug the filtering screen.

Once the system is sealed, a moderate flow (about $5 \mathrm{~L} / \mathrm{min}$ ) of nitrogen is fed into the feed and the bottom hoppers. The nitrogen flow is continued for 5 minutes after which it is reduced to a minimum. As the nitrogen flow is minimized, the primary product gas train is capped at its exit to prevent air from diffusing back into the system. At the same time the startup bypass valve is switched to the vacuum pump startup line and an air inlet valve is opened at the top of the reactor core. The power to the cartridge heater is turned on and the startup vacuum pump is turned on to pull air through the gasifier and over the cartridge heater. After an interval of 5-minutes the heater is turned off and its resistance is checked to determine if failure occurred during operation. Next, the air inlet valve is closed and oxygen flow is initiated at $10 \mathrm{~L} / \mathrm{min}$. Normally 2 minutes after oxygen initiation the ITZ can be detected. Once the ITZ has been confirmed to be 4 " above the lower flange on the gasifier core, the system is switched over to the primary product gas train and the oxygen flow is increased approximately $25 \mathrm{~L} / \mathrm{min}$. The ITZ is allowed to move upward to the first thermocouple, at which time the star valve drive is initiated at the slowest speed setting. The drive speed is increased as necessary to maintain the ITZ in the region of the first thermocouple.

While the unit is in steady state operating conditions, analysis procedures are initiated. Product gas samples are taken for bulk analysis and a portion of the product gas stream is diverted through the activated carbon trap for a period of time to sample any organics that might get through the gas train up to the flare.

To shut down the system, the oxygen flow is terminated and the star valve is turned off while the product gas stream is diverted directly to the hood. The nitrogen flow is increased to push out remaining oxygen and flammable gases from the core and primary product gas train. After a few minutes, the nitrogen flow is again reduced to a minimum for one hour. At the conclusion of this hour shut down is considered complete and the nitrogen flows are stopped.

After shut down the solid product, condensables, char in the filter, and the activated carbon are sampled and analyzed.

\section{Experimental}

\section{Characterization of Product:}

Similar methodologies were used for the analysis of the High Organic Sludge and the Neutral Aqueous Waste, so the discussion here applies to both wastes. The RCRA organic analyses were performed while operating the gasifier in the continuous feed mode The 
RCRA metals analyses were performed while operating the gasifier in the batch mode with only a condenser in the primary off gas train. Char/waste mixture ratios were 2:1 char/waste for the high organic sludge and 3:1 char/waste for the neutral aqueous waste.

The analyses can be divided in the three categories of (1) the RCRA organics, (2) RCRA metals, (3) and the product gas bulk composition. The possible locations for any undestroyed RCRA organics and byproducts include the spent solid product, the condensate isolated from cooling the gas stream, the char filter, and the activated carbon trap. For the RCRA metals the possible locations for recovered metals include the spent solid product and the condensables.

\section{RCRA Organics Analysis:}

Separation and determination of any undestroyed RCRA organics and byproducts were done with a Shimadzu GC 17A gas chromatograph using a Shimadzu QP-5000 mass spectrometer detector operating in the scan mode (GC/MS). The column used was a $30 \mathrm{~m}$, $0.25 \mathrm{~mm}$ I.D., DB-5ms capillary column. Quantitation was accomplished by the use of nitrobenzene as an internal standard. Calibration curves for all the compounds of interest were determined over a concentration range of $10 \mathrm{ppm}$ to $200 \mathrm{ppm}$. Instrument detection limits were calculated as the average blank plus three times the standard deviation of low level spike 3.

The three solids from the gasifier system in which the undestroyed RCRA organics and organic byproducts were measured were the spent solids, char filter, and activated carbon sampling tube. Duplicate samples from each of these sources were homogenized, and an accurately weighed portion of approximately $20 \mathrm{~g}$ of each solid was extracted by soxhlet extractor for $15-17$ hours with $110 \mathrm{~mL}$ of methylene chloride. The extract was dried with sodium sulfate and concentrated under vacuum to a volume that fell in the linear range of the calibration curve. The aqueous condensate product was extracted in a large separatory funnel with $3 \times 30 \mathrm{~mL}$ aliquots of methylene chloride. The extract was dried with sodium sulfate then concentrated under vacuum to an appropriate concentration for the instrument detection range.

RCRA Metals and Radionuclide Surrogates Analysis:

Atomic absorption spectroscopy (AA), atomic emission spectroscopy (AE), and Neutron Activation Analysis (NAA) were used to analyze the RCRA metals and radionuclide surrogates. Metals in the condensate product were stabilized with nitric acid to a pH of approximately 2. Metals were extracted from the solids with conc. nitric acid for $\mathrm{AA}$ and $\mathrm{AE}$ measurement. 
Atomic Absorption and Atomic Emission Analysis:

The presence of any lead, cadmium, nickel, chromium, and cesium in the condensate was determined with a Perkin-Elmer 5100PC atomic absorption instrument. All metals listed were analyzed by AA except cesium, which was analyzed by $\mathrm{AE}$ on the same instrument. The method of standard additions was used for quantification. The additions were made so that analyte concentrations in the solutions fell within the linear range of the selected wavelength. For cesium $1000 \mathrm{ppm}$ potassium chloride was added to suppress ionization. Instrument parameters are listed in Table 3.

Table 3. AA operation conditions.

\begin{tabular}{|c|c|c|c|c|c|c|}
\hline Metal & $\begin{array}{l}\text { Navelength, } \\
\mathrm{im}\end{array}$ & $\begin{array}{l}\text { Slit width, } \\
\mathrm{cm}\end{array}$ & Flame type & $\begin{array}{l}\text { Acetylene flow } \\
\mathrm{L} / \mathrm{min}\end{array}$ & $\begin{array}{l}\text { Air flow } \\
\mathrm{L} / \mathrm{min} \\
\end{array}$ & $\begin{array}{l}\text { Linear } \\
\text { range, } \mathrm{mg} / \mathrm{L}\end{array}$ \\
\hline Cadmium & 228.8 & 0.40 & Lean, blue & 10.00 & 2.00 & 2.0 \\
\hline Cesium & 852.1 & 0.40 & Lean, blue & 10.00 & 2.00 & 15.0 \\
\hline Chromium & 357.9 & 0.70 & Rich, yellow & 10.00 & 3.80 & 5.0 \\
\hline Lead & 283.3 & 0.70 & Lean, blue & 10.00 & 2.00 & 20.0 \\
\hline Nickel & 341.5 & 0.20 & Lean, blue & 10.00 & 2.00 & 10.0 \\
\hline
\end{tabular}

The condensate was prepared by taking a $1000 \mathrm{~mL}$ aliquot of the total condensable product, adding $30 \mathrm{~mL}$ hydrogen peroxide, and concentrating by heating to $250 \mathrm{~mL}$. These solutions were diluted 4-5 fold and the appropriate standard additions were made.

\section{Neutron Activation Analysis:}

Cerium, cesium, chromium, cadmium, and nickel were determined by neutron activation analysis (NAA) in both the spent char and the condensable product. A mass balance was calculated for each metal. Spent char, standards, and blanks were prepared for the solid product. The spent char sample preparation began with the homogenization of the sample. A quantity of 15-17 $\mathrm{g}$ of the homogenized char was placed in a polyethylene sleeve inside a pneumatic irradiation rabbit. The end of the polyethylene liner was closed, then the rabbit was sealed and irradiated for an appropriate length of time. Solid product standards were prepared by spiking an untreated char with a known quantity of the metal in an aqueous solution. The nitrate or chloride of the metal was used to correspond with the waste type being analyzed. After preparation the standards were packaged as described for the spent char sample. A blank of the untreated char was also processed. 
The condensate prepared for AA analysis was used for NAA analysis. Aliquots of 1$3 \mathrm{~mL}$ were taken and evaporated to dryness in polyethylene vials. Standards were prepared in similar polyethylene vials to obtain $0.100 \mathrm{mg}$ of nickel, chromium, and cadmium and $0.010 \mathrm{mg}$ of cesium and cerium after evaporation.

\section{Bulk Product Gas Analysis:}

Bulk gas product composition, including carbon dioxide, carbon monoxide, hydrogen, methane, and nitrogen, was determined with a Shimadzu GC 14A gas chromatograph using a thermal conductivity detector. The carrier gas used was argon. The column used for separation was Carbosphere $80 / 1006^{*} 1 / 8 " * 0.085 "$ molecular sieve. The sample loop was an air actuated $1 \mathrm{~mL}$ gas sampling system. Samples were taken during gasification runs from the gas sampling port downstream from the char filter in a gas-tight syringe and immediately analyzed. Calibration curves were produced using pure gas standards.

\section{Results, Conclusions, and Discussion}

\section{Solid Product Flow Rates:}

The throughput of the system was measured by the amount of char-waste and waste that can be treated by the system over a period of time. The type of waste plays a large role in determining throughput. The quantity of waste components, such as water and flammable organic compounds, has the largest influence on throughput. A high aqueous waste lowers the gasification temperatures and slows the gasification process. For the 4" ChemChar gasifier typical throughput for the high organic waste is 14 to $15 \mathrm{~kg}$ per hour of a $2: 1 \mathrm{char} /$ waste mixture. For the neutral aqueous waste the throughput is 7 to $8 \mathrm{~kg}$ per hour at a 3:1 char/waste mixture.

\section{$\underline{\text { RCRA Organic Distribution and DRE: }}$}

The DREs and the distribution of undestroyed RCRA organic components are shown in Table 4. For all cases for DRE, the calculation is based on the detection limit for the method. For all three organic surrogates in the neutral aqueous waste the DRE is greater than $99.99 \%$ (4-nines) and in the case of the high organic sludge the DRE is greater than 99.999\% (5-nines). Trace levels of organic byproducts such as benzene, toluene, and, xylene have been detected on the spent char, and some phenols have been detected in the condenser. No byproducts were detected past the char filter. The data indicates the system is operating efficiently, trapping any of the undestroyed RCRA organic and/or process 
byproduct inside of the system. The system components, including the spent char, the char filter, and the condensable material, are recycled in subsequent runs to obtain the complete destruction of the organics.

Table 4a: The Distribution and \% DRE for the RCRA Organic Components of DOE Neutral Aqueous Waste.

Mass of organic gasified, g

Mass of organic recovered from, $\mathrm{g}$

\begin{tabular}{lccc} 
Spent char $(\mathrm{g})$ & $8.67 \mathrm{E}-04$ & $5.78 \mathrm{E}-0 ?$ & $3.86 \mathrm{E}-03$ \\
Condenser $(\mathrm{g})$ & $2.28 \mathrm{E}-05$ & $6.45 \mathrm{E}-05$ & $6.63 \mathrm{E}-04$ \\
Filter $(\mathrm{g})$ & $3.35 \mathrm{E}-03$ & $5.71 \mathrm{E}-04$ & $4.82 \mathrm{E}-02$ \\
Activated Carbon* & $3.0530 \mathrm{E}-05$ & $1.6695 \mathrm{E}-05$ & $2.9981 \mathrm{E}-05$ \\
\% DRE & 99.9967 & 99.9982 & 99.9976 \\
\hline
\end{tabular}

* Less than values based on method detection limit.

Table 4b: The Distribution and \%DRE for the RCRA Organic Components of DOE High Organic Sludge.

Mass of organic

gasified, $\mathrm{g}$

Chlorobenzene Dichlorobenzene Naphthalene

54.612

54.612

81.918

Mass of organic recovered from, $\mathrm{g}$

\begin{tabular}{llll} 
Spent char $(\mathrm{g})$ & 0.243 & 0.352 & 0.416 \\
Condenser $(\mathrm{g})$ & $1.06 \mathrm{E}-02$ & $4.08 \mathrm{E}-03$ & $7.74 \mathrm{E}-03$ \\
Filter $(\mathrm{g})$ & 8.72 & 3.28 & 3.82 \\
Activated Carbon* & $3.1201 \mathrm{E}-05$ & $1.7061 \mathrm{E}-05$ & $3.0639 \mathrm{E}-05$ \\
\% DRE & 99.9995 & 99.9997 & 99.9997 \\
\hline
\end{tabular}




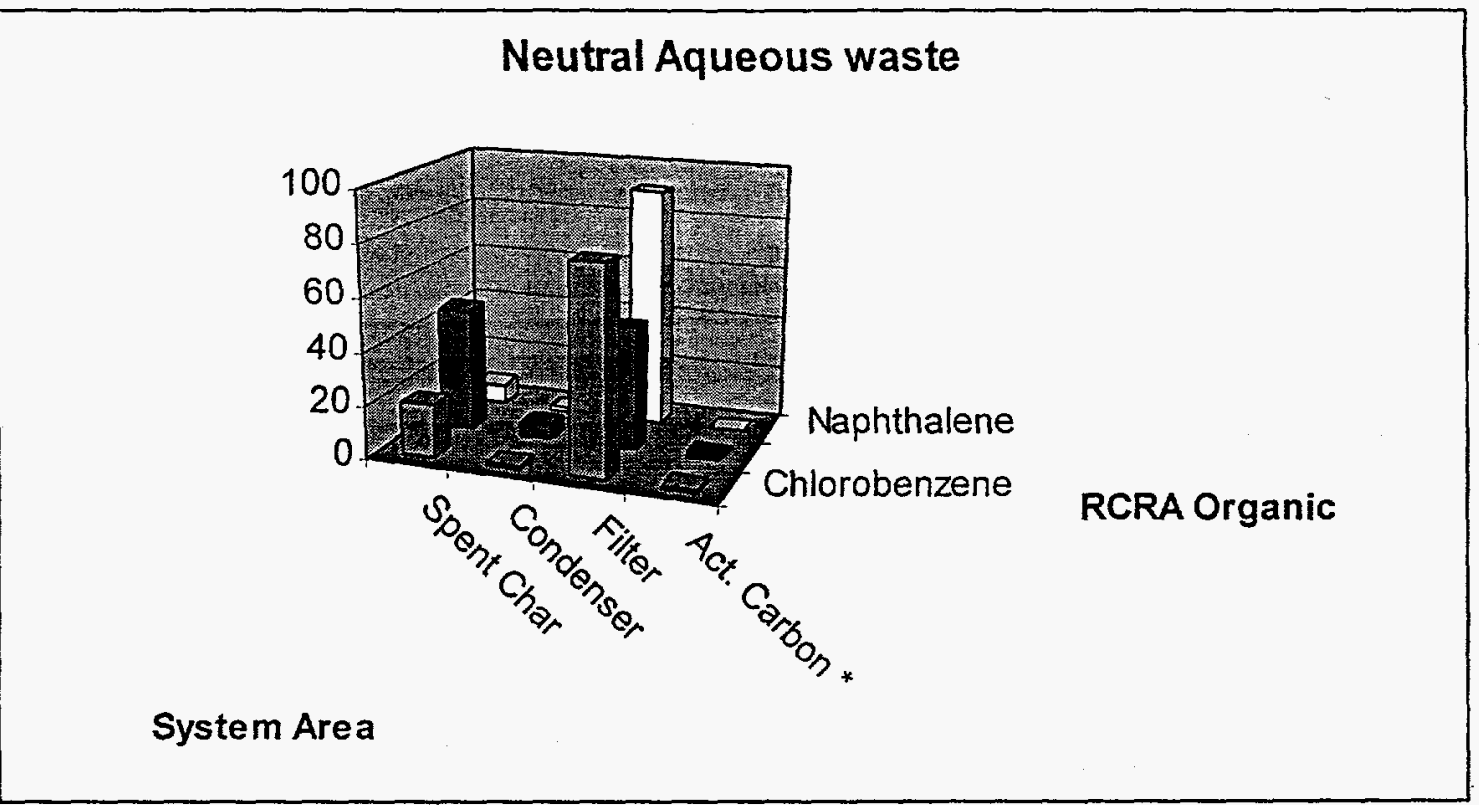

Figure 5. Distribution of Undestroyed RCRA Organics for the Neutral Aqueous Waste.

\section{High Organic Sludge}

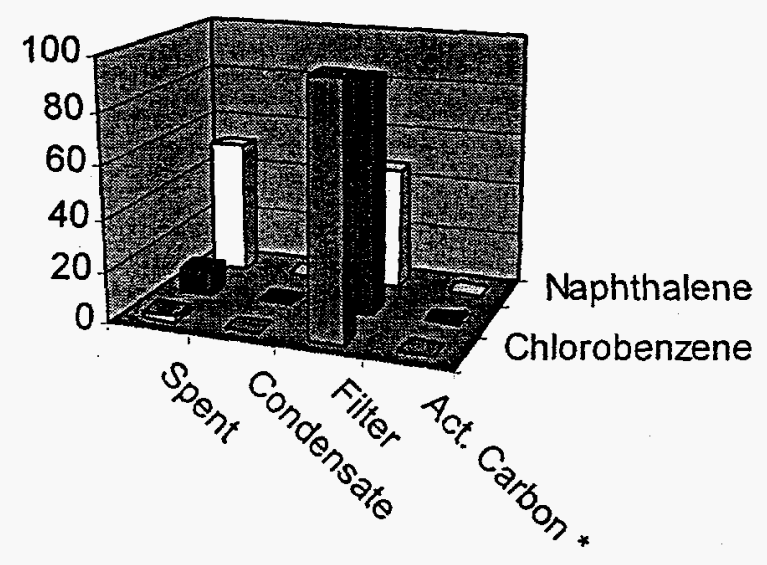

RCRA Organic

System Area

Figure 6: Distribution of Undestroyed RCRA Organics for the High Organic Sludge. 
RCRA Metals and Radionuclide Surrogate Partitioning:

In general, as shown in Table 5, for the five metals examined using AA and AE, it is seen that greater than $99 \%$ of the metal is retained on the char substrate. For all the metals but cadmium the values are based on less than values determined by the method detection limit. These values suggest that very little metal is volatized and primarily stay within the gasification system.

Table 5. Distribution of RCRA Metals and During Gasification

\begin{tabular}{lllll} 
Metal & $\begin{array}{l}\text { Initial } \\
\text { loading, g }\end{array}$ & $\begin{array}{l}\text { Percent on } \\
\text { column (NAA) }\end{array}$ & $\begin{array}{l}\text { Percent in } \\
\text { condensate }(\mathrm{NAA})^{2}\end{array}$ & $\begin{array}{l}\text { Percent in } \\
\text { condensate (AA/AE) }\end{array}$ \\
\hline
\end{tabular}

Neutral Aqueous Waste

$\begin{array}{lcccc}\text { Cesium } & 0.66 & 105.99 \pm 8.17 & 0.002 \pm 0.003 & <0.006^{4} \\ \text { Cerium } & --- & 109.23 \pm 9.02 & 0.0056 \pm 0.003 & \mathrm{n} / \mathrm{a} \\ \text { Chromium } & 0.109 & 114.66 \pm 21.78 & 0.088 \pm 0.047 & <0.1^{4} \\ \text { Cadmium } & 0.305 & 104.63 \pm 10.04 & 0.174 \pm 0.048 & 0.186 \\ \text { Nickel } & 0.169 & 86.47 \pm 3.14 & <0.086^{4} & <0.1^{4} \\ \text { Lead } & 0.523 & \mathrm{n} / \mathrm{a} & \mathrm{n} / \mathrm{a} & <0.09^{4}\end{array}$

High Organic Waste

$\begin{array}{lcccc}\text { Cesium } & 0.992 & 87.51 \pm 3.30 & 0.002 \pm 0.0002 & <0.004^{4} \\ \text { Cerium } & -- & 98.96 \pm 9.40 & 0.003 \pm 0.0004 & \mathrm{n} / \mathrm{a} \\ \text { Chromium } & 0.245 & 94.35 \pm 20.01 & 0.052 \pm 0.026 & <0.04^{4} \\ \text { Cadmium } & 0.617 & 88.20 \pm 5.08 & 0.244 \pm 0.033 & 0.30 \\ \text { Nickel } & 0.31 & 93.91 \pm 14.96 & <0.006^{4} & <0.06^{4} \\ \text { Lead } & 0.933 & \mathrm{n} / \mathrm{a} & \mathrm{n} / \mathrm{a} & <0.05^{4}\end{array}$

1 Percent of initial metal loading recovered from the column as measured by neutron activation analysis

2 Percent of initial metal loading recovered from the condensate as measured by neutron activation analysis

3 Percent of initial metal loading recovered from the condensate as measured by atomic spectrophotometric analysis

4 Less than values based on method detection limit. 
Temperature Profiles:

Although the original gasifier design was intended to provide a comprehensive temperature profile, the large number of thermocouples embedded in the original ceramic core responded very slowly and inaccurately to conditions inside the core. Thus, a particular thermocouple might respond several minutes after the ITZ passed by it, so that its reading was useless, both for establishing a thermal profile and for regulating the feed through the gasifier.

The simpler system of temperature monitoring actually used in testing the gasifier employed only three thermocouples. Two of these were inserted through the gasifier core wall, one half-way up the core, and the other near the top of the core. A third thermocouple was inserted from the top down through the center of the core, and was located midway between the two thermocouples mounted in the core walls. For convenience in discussion, these will be designated Thermocouples 1,2 , and 3, respectively.

It was concluded that the thermocouple readings did not give accurate measurements of temperature because in no case were readings above $400^{\circ} \mathrm{C}$ obtained, whereas temperatures of around $1200^{\circ} \mathrm{C}$ must be reached to sustain the ITZ. Therefore, the thermocouple readings were used primarily to discern' the location of the ITZ. In this respect they functioned very well. The responses of Thermocouples 1 and 2 were somewhat slow because of their contact with the core walls. The response of Thermocouple 3 was especially useful in determining the location of the ITZ. As the ITZ reached the thermocouple, the temperature increased very rapidly and sharply, consistent with the passage over the thermocouple surface of a sharp leading edge on the ITZ as observed in the laboratory. As spent char was removed from the gasifier, causing the ITZ to move downward relative to the gasifier walls, the reading on Thermocouple 3 decreased relatively rapidly as it contacted cool, ungasified char/waste mixture. Therefore, one thermocouple, alone, enabled monitoring of the ITZ and maintenance of its location within a narrow range in the reactor core. The mode of operation was simply to wait until the temperature reading on Thermocouple 3 ramped upward sharply, run spent char out the bottom of the gasifier until the reading on the thermocouple began to decrease showing that the ITZ had moved below it, then repeating the cycle when the reading on Thermocouple 3 increased again. Although these operations were performed manually, they are very well adapted to automated operation.

The sharpness of the ITZ leading edge was monitored in an unsophisticated, but effective manner by observing the evaporation of water injected onto the outer surface of the gasifier core. This method is illustrated in Figure 7. 


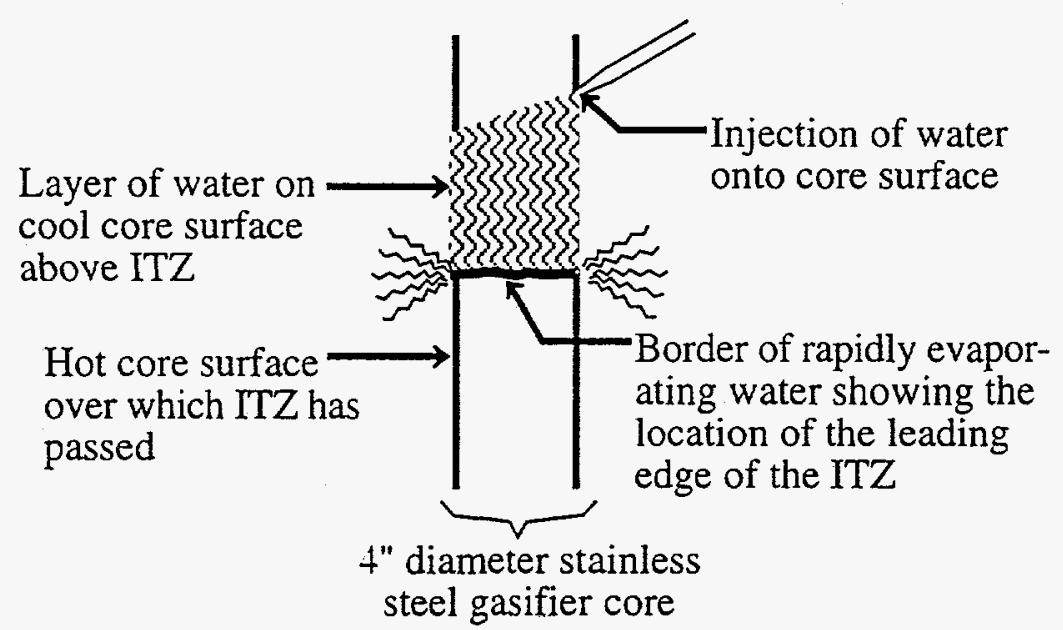

Figure 7. Observation of the leading edge of the ITZ by evaporation of water injected onto the outer surface of the gasifier core.

Product gas flow rates and composition:

During a typical gasification of a char-waste mixture the oxygen feed rate is $25 \mathrm{~L} / \mathrm{min}$. Total product gas flow rates normally are double the oxygen input volume ranging from 45 to $55 \mathrm{~L} / \mathrm{min}$. The primary components of the product gas have been determined by $\mathrm{GC}$ to be hydrogen, carbon dioxide, carbon monoxide, nitrogen, water, and methane as shown in Table 1-5. The nitrogen component can primarily be attributed to the flows put into the feed hopper and the lower hopper. The quantity of the water component of the product gas is not readily determined experimentally.

The carbon monoxide/carbon dioxide ratio is a good indicator of temperature equilibrium for the system and those found in this study suggest equilibrium temperatures in the range from $640^{\circ}$ to $675^{\circ} \mathrm{C}$. But other factors, such as water content, can effect the temperature of the gasification process thus effecting the final composition of the gas. ${ }^{6}$

Table 6. Mole Fraction of Product Gas.

Gas in product Mole fraction of gas in product

Hydrogen

0.306

Nitrogen

0.043

Carbon Monoxide

0.347

Methane

0.010

Carbon Dioxide

0.307 
Conclusions:

The 4" continuous feed ChemChar gasifier has successfully gone through modification and shakedown as specified by Cooperative Agreement DE-FC2196MC33258 between the U.S. Department of Energy and ChemChar Research, Inc. The gasifier has proven to be functional in design by successfully treating two formulations of surrogate mixed wastes and achieving at least 4-nines DRE of the RCRA organic compounds, while retaining over $99 \%$ of the RCRA metals and surrogate radionuclides on the char substrate. Simplification of the system has made the gasifier easier and safer to operate. Much of the effort applied to the process was in the development of methodology and safety provisions.

The char substrate, the key element of the process, was found to successfully sequester the waste and make it easier to handle at ratios of 2:1 char-waste for the high organic sludge and 3:1 char-waste for the neutral aqueous waste. The ability to recycle the char for subsequent gasifications makes loadings such as these viable.

The analysis for each gasification was divided into three categories; (1) the RCRA organics, (2) RCRA metals and radionuclide surrogates, (3) and the product gas bulk composition. No byproducts or significant amount of RCRA organic compounds were detected past the char filter. The bulk gas product analysis showed the gas to be a usable synthesis gas with heating values around 300 BTU per SCF making cost recovery viable from waste cleanup operations.

The investigators believe that the ChemChar system has been developed to a stage at which it can now be scaled up to the minimum practical industrial size of 1 -foot diameter and used in a practical manner to treat low level mixed wastes.

\section{References}

1. Bostick, W. D., et al., Surrogate Formulations for Thermal Treatment of LowLevel Mixed Waste, Part II: Selected Mixed Waste Treatment Project Waste Streams, U.S. Department of Energy, DE-AC05-84OR21400.

2. "Reverse-Burn Gasification for Treatment of Hazardous Wastes: Contaminated Soil, Mixed Wastes, and Spent Activated Carbon Regeneration," Laura L. Kinner, Audrey McGowin, Stanley E. Manahan, David W. Larsen and Environmental Science and Technology, 27, 482-488 (1993).

3. "Mixed Waste Treatment by Reverse-Burn Gasification," Audrey McGowin, Christopher Cady, Stanley E. Manahan. and David W. Larsen, Chemosphere, 27(5), 779-794, (1993). 
4. "Gasification of Waste-Contaminated Soil by the ChemChar Process," Laura L. Kinner, David W. Larsen and Stanley E. Manahan, J. Environmental Science and Health, A28, 697-727 (1993) .

5. "Mechanistic Study of the ChemChar Process Using Hexachlorobenzene as a Surrogate for Monitoring Reaction Products," Laura L. Kinner, Stanley E. Manahan, and David W. Larsen, Chemosphere, 24(12), 1867-1884 (1992).

6. Medcalf, Bradley D., The ChemChar Gasification Process: Theory, Experiment, and Design Developments, Ph.D. Dissertation, University of Missouri-Columbia, May, 1998. 